\title{
Drought Effects on Green Pea Texture and Related Physical-Chemical Properties at Comparable Maturity
}

\author{
J.N. Sorensen ${ }^{1}$ and M. Edelenbos \\ Danish Institute of Agricultural Sciences, Department of Horticulture, DK-5792 Aarslev, Denmark
}

L. Wienberg

The Royal Veterinary and Agricultural University, Department of Dairy and Food Science, DK-1958 Frederiksberg C, Denmark

\begin{abstract}
AdDitional index words. Pisum sativum, alcohol-insoluble solids, cultivar, green peas, developmental stage, drought stress, irrigation, quality, sensory attributes, starch, sucrose

Aвstract. Yield and seed texture were studied in green peas (Pisum sativum L.) subjected to drought stress during flowering and pod filling. Field experiments were conducted with two cultivars on a sandy loam soil and drought conditions were obtained using movable rain shelters. The plants were harvested at three to five stages of maturity determined by tenderometer values and the concentration of alcohol-insoluble solids (AIS). Measured variables were related to the concentration of AIS in order to eliminate the influence of maturity when comparing between stress and nonstress conditions. Drought stress during flowering or pod filling reduced yield, but did not affect the size distribution consistently. To lessen the differences caused by variation in size distribution, all quality measurements were carried out on peas graded to 8.75 to

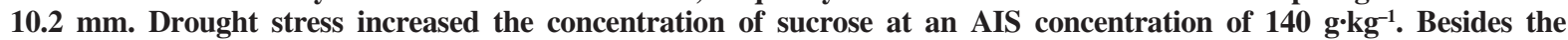
concentration of dry matter and starch the mean pea weight and testa weight did not reflect any consistency in relation to drought-stress conditions. The sensory scores for pea mealiness was not significantly increased in drought stress, and other sensory quality attributes were unaffected. In this study, the effect of drought stress on pea texture quality is weak and inconsistent when comparisons are made at the same stage of maturity. As texture quality is highly correlated to stage of maturity, the tenderometer value or AIS concentration is reliable when determining time of harvest for the production of high quality peas irrespective of drought-stress conditions during maturation.
\end{abstract}

Textural properties such as crispness and mealiness are quality criteria considered important in food acceptability. In green peas (Pisum sativum L.), mealiness and tenderness have been shown to be influenced by cultivar, pea size, and maturity at harvest (Kidmose and Grevsen, 1992; Kjølstad et al., 1990; Ottosson, 1958; Periago et al., 1996). Therefore, time of harvest is based on the tenderness of the peas as evaluated with a mechanical tenderometer (Martin, 1937). However, the concentration of alcoholinsoluble solids (AIS), which usually describes the tenderness of processed peas, has proven to be an even more reliable method for determining the maturity of green peas (Periago et al., 1996; Voisey and Nonnecke, 1973). In addition, Ottosson (1958) found that use of the AIS method as a criterion for the harvest time was less dependent on weather conditions (wet or dry soil).

Pea crops exposed to drought during the reproductive growth stage yield poorly because of flower and pod abortion (Maurer et al., 1968; Pumphrey and Schwanke, 1974; Salter, 1963; Stoker, 1973). In Denmark, green peas are not usually irrigated, and in the early 1990s several dry growing seasons reduced yield and overall pea quality, thereby contributing to a considerable reduction in total pea area in the mid-1990s (Forskningsforeningen, 1999). The diminished quality was caused by too rapid an increase in maturity in relation to the harvest and processing capacity of the freezing industry.

Drought stress can enhance maturation and thus the chemical composition of green peas. Ottosson (1958) showed that the dry matter, starch, and sugar concentrations in green peas were influenced by maturity. Drought stress can also have a direct effect on the chemical composition. Although the concentration of water in plants decreases as a result of dehydration, the

Received for publication 8 Mar. 2002. Accepted for publication 24 Sept. 2002. 'Corresponding author: e-mail JornN.Sorensen@agrsci.dk. concentrations of organic constituents such as sugars and amino acids can increase, e.g., active accumulation (Morgan, 1984; Sánchez et al., 1998). However, it is difficult to distinguish between direct and indirect effects of drought stress and this has not been done so far. Salter (1963), however, eliminated the indirect effects of drought stress on yield components by interpolation.

Drought stress effects on yield and chemical composition of green peas have been extensively studied previously (Martin and Tabley, 1981; Maurer et al., 1968; Pumphrey and Schwanke, 1974; Salter, 1963; Stoker, 1973). So far, elimination of maturity differences when comparing stress and nonstress conditions has not been made. The objective of this study was to describe the changes in texture quality of green peas at comparable maturity as influenced by drought stress. The texture quality of stressed and nonstressed peas was determined at comparable pea size and AIS level. The proportion of testa of the total pea weight and the starch and dry matter concentration were used to describe the physical-chemical texture quality in addition to mealiness and other sensory attributes (Edelenbos et al., 2001; Periago et al., 1996).

Table 1 . Deficit ${ }^{\mathrm{z}}$ in the 0 to $50 \mathrm{~cm}$ soil layer in percentage of plant available water at field capacity.

\begin{tabular}{lccccc}
\hline \hline & \multicolumn{4}{c}{ Deficit (\%) } \\
\cline { 2 - 3 } \cline { 5 - 6 } Drought period & \multicolumn{2}{c}{1995} & & \multicolumn{2}{c}{1996} \\
\cline { 2 - 3 } \cline { 5 - 6 } & Avola & Novella & & Avola & Novella \\
\hline Flowering & 63 & 72 & & $---{ }^{y}$ & --- \\
Pod filling & 67 & 79 & & 83 & 86 \\
\hline
\end{tabular}

${ }^{\mathrm{Z}}$ Deficits of $60 \%, 70 \%, 80 \%$, and $90 \%$ corresponds to soil water potentials of $-0.30,-0.45,-0.62$, and $-0.80 \mathrm{MPa}$, respectively.

${ }^{\mathrm{y}} \mathrm{No}$ drought stress applied. 


\section{Materials and Methods}

Treatments AND GROWTH CONDITIONS. Field experiments on drought stress in wrinkle-seeded peas (Pisum sativum L.) were conducted in two years. In 1995, drought stress was imposed during the flowering or the pod-filling stages in two cultivars, and in 1996 during the pod-filling stage only. Stress conditions were obtained using movable rain shelters constructed of a mobile polyethylene fabric covering an area $6 \times 10 \mathrm{~m}$. The rain shelters were only activated during rain showers. Guard areas $1 \mathrm{~m}$ wide were used to counter any effects of rainwater entering through the sides of the shelter and lateral soil water movements. Each sheltering period lasted between four and six weeks.

The two cultivars were 'Avola' and 'Novella'. 'Avola' (Asgrow Seed Co.) is an indeterminate and normal-leafed pea type, whereas 'Novella' (Sluis \& Groot BV, The Netherlands) is semi-fasciated and semi-leafless. Seeds were sown at the beginning of May in rows $12 \mathrm{~cm}$ apart. 'Novella' was sown $12 \mathrm{~d}$ before 'Avola' as 'Novella' has an approximate $12 \mathrm{~d}$ longer growing period until flowering than 'Avola'. The established crop density was approximately 100 plants $/ \mathrm{m}^{2}$. Base dressings of preplant-applied $\mathrm{P}, \mathrm{K}$, and $\mathrm{Mg}$ were 40 , 210, and $46 \mathrm{~kg} \cdot \mathrm{ha}^{-1}$ each year, respectively. Annual weeds were controlled by spraying with a mixture of bentazon (BASF, Denmark; $1.5 \mathrm{~L} \cdot \mathrm{ha}^{-1}$ ) and pendimethalin (Cyanamid, Denmark; 4.0 $\left.\mathrm{L} \cdot \mathrm{ha}^{-1}\right)$. When necessary, the plants were sprayed with alphacypermethrin (Cyanamid, Denmark; $0.125 \mathrm{~L} \cdot \mathrm{ha}^{-1}$ ) against pea weevils and pea moth caterpillars.

No water was applied during drought-stress periods. The deficits obtained during these periods are given in Table 1. During nonstress periods, the plants were irrigated when the deficit of plant-available water at field capacity reached $30 \%$, corresponding to a soil water potential of $-0.06 \mathrm{MPa}$. Control plots were irrigated when deficits reached $30 \%$ throughout the growing period.

The contents of plant-available water in the upper 25, 50, and 75 $\mathrm{cm}$ soil profiles were 49, 93, and $131 \mathrm{~mm}$ at field capacity, respectively. Soil moisture was measured using time-domain reflectometry (TDR) (Soilmoisture Equipment Corp., Santa Barbara,
Calif.). The TDR rods were placed vertically in soil layers of $25 \mathrm{~cm}$, and the deficit in the 0 to $50 \mathrm{~cm}$ soil layer was used to determine the amount of irrigation water to be applied. Irrigation was not necessary during the vegetative growth stage in either year. A trickle irrigation system (Netafim, Israel) was used, enabling infiltration of the soil without any surface runoff. Each treatment was individually irrigated to field capacity. In 1995, nonstressed 'Avola' and 'Novella' received 223 and $240 \mathrm{~mm}$ of water, respectively, from rainfall or irrigation. In 1996, 'Avola' and 'Novella' received 212 and 254 $\mathrm{mm}$, respectively.

A sandy loam soil was used in both experiments. The content of clay, silt, sand, coarse sand, and organic matter in the top $25 \mathrm{~cm}$ soil was $110,145,558,163$, and $24 \mathrm{~g} \cdot \mathrm{kg}^{-1}$, respectively. The bulk density was $1.5 \mathrm{~g} \cdot \mathrm{cm}^{-3}$ and the $\mathrm{pH}$ was in the range of 6.5 to 6.8 . The initial content of mineral nitrogen $\left(\mathrm{N}_{\text {min }}\right), \mathrm{P}, \mathrm{K}$, and $\mathrm{Mg}$ in the top $25 \mathrm{~cm}$ soil was in the range of 6 to 9,43 to 49,210 to 240 , and 48 to $67 \mathrm{mg} \cdot \mathrm{kg}^{-1}$ dry soil, respectively. Potassium and magnesium were extracted with ammonium acetate and phosphorus with sodium bicarbonate (Sørensen and Bülow-Olsen, 1994). The $\mathrm{N}_{\min }$ content was determined in accordance with the methods of Best (1976) and Crooke and Simpson (1971).

The plants were harvested at approximate tenderometer values (TV) of 90, 100, and 110 in 1995, and 80, 90, 100, 110, and 120 in 1996. From this material, size graded peas at comparable maturity were selected for analysis. In 1995, the experiment was arranged in a split-split plot design with three replicates. Cultivar was the main plot, drought period the subplot, and maturity at harvest the subsubplot. Net plot size was $3.3 \mathrm{~m}^{2}$. In 1996, the experiment was arranged in a split plot design with three replicates. Cultivar and drought period were main plots and maturity at harvest the subplot. Net plot size was 3.8 to $5.1 \mathrm{~m}^{2}$.

Weather conditions. The climate at the experimental site is temperate coastal. Precipitation during the growing season was 187 $\mathrm{mm}$ in 1995 and $153 \mathrm{~mm}$ in 1996. Rate of evapotranspiration influenced the duration of sheltering, which averaged $3 \%$ during each stress period and ranged from $0 \%$ to $7 \%$. Photosynthetically active radiation above the canopy was reduced by $\approx 25 \%$ during

Table 2. Content of alcohol-insoluble solids (AIS), yield and size distribution of ungraded peas from two cultivars harvested in 1995 and 1996 from nonstressed treatments of varying maturities as indicated by tenderometer value. Standard errors are based on a sample size of three.

\begin{tabular}{|c|c|c|c|c|c|c|c|}
\hline \multirow[b]{2}{*}{ Year } & \multirow{2}{*}{$\begin{array}{c}\text { Tenderometer } \\
\text { value }\end{array}$} & \multirow{2}{*}{$\begin{array}{c}\text { AIS } \\
\left(\mathrm{g} \cdot \mathrm{kg}^{-1}\right)\end{array}$} & \multirow{2}{*}{$\begin{array}{c}\text { Pea } \\
\text { yield } \\
\left(\mathrm{Mg} \cdot \mathrm{ha}^{-1}\right)\end{array}$} & \multicolumn{4}{|c|}{ Size distribution $(\%)$} \\
\hline & & & & $<8.2 \mathrm{~mm}$ & $8.2-8.74 \mathrm{~mm}$ & $8.75-10.2 \mathrm{~mm}$ & $>10.2 \mathrm{~mm}$ \\
\hline & & & & Avola & & & \\
\hline \multirow[t]{3}{*}{1995} & $104 \pm 0.9$ & $129 \pm 3.0$ & $5.3 \pm 0.22$ & $10 \pm 2.0$ & $11 \pm 1.2$ & $68 \pm 1.4$ & $11 \pm 2.1$ \\
\hline & $116 \pm 1.2$ & $143 \pm 2.8$ & $6.5 \pm 0.08$ & $7 \pm 1.2$ & $10 \pm 0.9$ & $66 \pm 3.7$ & $18 \pm 5.0$ \\
\hline & $133 \pm 1.7$ & $157 \pm 0.9$ & $6.5 \pm 0.16$ & $5 \pm 1.2$ & $8 \pm 1.0$ & $58 \pm 9.2$ & $29 \pm 11.2$ \\
\hline \multirow[t]{6}{*}{1996} & $88 \pm 1.2$ & $107 \pm 2.5$ & $3.7 \pm 0.16$ & $24 \pm 1.3$ & $21 \pm 1.0$ & $48 \pm 1.6$ & $7 \pm 1.5$ \\
\hline & $91 \pm 2.0$ & $108 \pm 3.4$ & $4.1 \pm 0.66$ & $20 \pm 2.4$ & $21 \pm 1.0$ & $52 \pm 2.5$ & $7 \pm 1.1$ \\
\hline & $98 \pm 3.1$ & $129 \pm 5.3$ & $5.1 \pm 0.42$ & $14 \pm 1.7$ & $17 \pm 1.4$ & $55 \pm 0.8$ & $14 \pm 2.5$ \\
\hline & $104 \pm 2.9$ & $129 \pm 3.1$ & $6.5 \pm 0.68$ & $8 \pm 1.6$ & $13 \pm 0.7$ & $62 \pm 3.0$ & $17 \pm 1.3$ \\
\hline & $113 \pm 3.2$ & $144 \pm 2.3$ & $7.0 \pm 0.72$ & $5 \pm 0.9$ & $10 \pm 1.2$ & $64 \pm 2.2$ & $20 \pm 2.2$ \\
\hline & & & & Novella & & & \\
\hline \multirow[t]{3}{*}{1995} & $103 \pm 1.1$ & $127 \pm 1.8$ & $8.6 \pm 0.31$ & $25 \pm 2.8$ & $21 \pm 0.9$ & $52 \pm 2.7$ & $2 \pm 0.4$ \\
\hline & $112 \pm 1.6$ & $133 \pm 2.4$ & $8.6 \pm 0.22$ & $19 \pm 3.1$ & $19 \pm 1.0$ & $59 \pm 3.0$ & $3 \pm 1.0$ \\
\hline & $111 \pm 2.5$ & $138 \pm 1.5$ & $9.3 \pm 0.02$ & $17 \pm 1.7$ & $17 \pm 0.8$ & $62 \pm 1.2$ & $4 \pm 1.4$ \\
\hline \multirow[t]{5}{*}{1996} & $92 \pm 1.7$ & $113 \pm 2.5$ & $8.1 \pm 0.13$ & $31 \pm 2.7$ & $23 \pm 0.9$ & $45 \pm 3.2$ & $2 \pm 0.3$ \\
\hline & $96 \pm 1.3$ & $115 \pm 3.7$ & $7.9 \pm 0.19$ & $28 \pm 1.4$ & $20 \pm 0.8$ & $51 \pm 1.8$ & $1 \pm 0.4$ \\
\hline & $105 \pm 1.8$ & $132 \pm 4.3$ & $8.7 \pm 0.46$ & $22 \pm 2.0$ & $18 \pm 0.5$ & $57 \pm 1.1$ & $3 \pm 1.5$ \\
\hline & $115 \pm 1.4$ & $143 \pm 2.1$ & $11.1 \pm 0.23$ & $12 \pm 1.6$ & $16 \pm 0.5$ & $66 \pm 0.8$ & $6 \pm 2.1$ \\
\hline & $124 \pm 3.7$ & $157 \pm 8.2$ & $11.1 \pm 0.08$ & $8 \pm 1.7$ & $11 \pm 1.2$ & $71 \pm 1.5$ & $10 \pm 2.2$ \\
\hline
\end{tabular}


sheltering. No differences were observed in air and soil temperatures below and outside the shelters. In 1995, mean air temperature was below normal during the vegetative growth period (June), but above normal during the harvest period. During the growth period in 1996 the mean air temperature was below normal, except at the germination and emergence stages (beginning of May) and at the end of the vegetative period (middle of June).

HARVEST. Plants were harvested at the end of July. The harvested plants were threshed in a mini viner (Schepers Techniek, Hoogeveen, The Netherlands) and the peas were washed in a rotating drum with perforations $6.0 \mathrm{~mm}$ in diameter. Total pea fresh weight was recorded and the maturity level of ungraded peas was determined on a pea tenderometer (Martin; FMC Food Machinery, Parma, Italy) and by AIS analysis. Ungraded peas, 60 to $100 \mathrm{~g}$, were blanched for 2 min at $95^{\circ} \mathrm{C}$ and frozen at $-24^{\circ} \mathrm{C}$ for the AIS analysis.

The remaining peas were graded into four size categories $(<8.2$, 8.2 to $8.74,8.75$ to 10.2 , and $>10.2 \mathrm{~mm}$ in diameter) using a Jel shaking instrument (Engelsmann, Ludwigshafen, Germany) with four stainless-steel sieves placed one on top of the other. The peas were shaken at $285 \mathrm{rpm}$ for 3 min with an amplitude of $15 \mathrm{~mm}$ and the fresh weight of each size category was recorded. All pea sizes were processed in 1995, i.e., blanched in steam at $95^{\circ} \mathrm{C}$ for $1.5,2.0$, 2.5 , or 3.0 min depending on size until peroxidase was inactivated (Kidmose and Grevsen, 1992), cooled, frozen in an air-blast freezer (Gram KPS 720 RHAV/FAV; Vojens, Denmark), packed in mylothene mirrorprint pouches (M-PETP; Danisco Flexible, Horsens, Denmark), and stored at $-24^{\circ} \mathrm{C}$. In 1996 , only the 8.75 to $10.2 \mathrm{~mm}$ size category was processed. All physical, chemical, and sensory analyses were carried out on processed and thawed peas, unless otherwise stated.

Physical, Chemical and sensory analysis. Testa weight of the total pea weight was determined on 20 to $50 \mathrm{~g}$ of peas (Edelenbos et al., 2001). The testa was separated by hand from the cotyledons and the total weight recorded. The number of peas in the sample was counted and the weight per pea calculated.

Samples were analysed for AIS using a simplified version of the standard AOAC method for canned peas (AOAC, 1990). Twenty grams of peas were blended with $20 \mathrm{~mL}$ distilled water for $90 \mathrm{~s}$ in a homogenizer ( Ultra-Turrax; Ika-Labortechnik, Staufen, Germany). From this homogenate $10 \mathrm{~g}$ were washed with $100 \mathrm{~mL} 80 \%$ ethanol (w/w). The rinsed residues were filtered under vacuum and dried at $115^{\circ} \mathrm{C}$ to constant weight. Dry matter was determined in a 10 -g sample by forced air convection at $80^{\circ} \mathrm{C}$ for $16 \mathrm{~h}$. Total starch concentration was determined by enzymatic hydrolysis of pea flour $(50 \mathrm{mg})$ to glucose (Edelenbos et al., 2001).

Sucrose was analysed using high-pressure liquid chromatography (HPLC) coupled to a RID-6A refractive index detector. Extracts were prepared from 10-g samples of thawed peas homogenized with $18 \mathrm{~mL}$ distilled deionized water (Elga Ldt., Bucks, England) for 60 $\mathrm{s}$ in a homogenizer. The homogenate was centrifuged for $10 \mathrm{~min}$ at $4^{\circ} \mathrm{C}$ and $20,845 g_{\text {n }}$ using a head (SA-600; Heraeus Sorvall, Albertslund, Denmark) to separate the supernatant from solids. The supernatant was removed and solids re-extracted twice in $25 \mathrm{~mL}$ distilled deionized water. The combined supernatants were adjusted to $100 \mathrm{~mL}$ with distilled deionized water and filtered through Whatman no. 1 filter paper. For HPLC analysis, $2.5 \mathrm{~mL}$ of the extract was mixed with 7.5 $\mathrm{mL}$ HPLC-grade acetonitrile, filtered through a 0.45- $\mu \mathrm{m}$ filter (Minisart SRP 25; Sartorius
AG, Göttingen, Germany), and injected into a HPLC system (Shimadzu Corp., Kyoto, Japan) equipped with Supelcosil LC-NH $\mathrm{N}_{2}$ guard $(20 \times 4.6 \mathrm{mmi}$.d., $5 \mu \mathrm{m})$ and analytical columns $(250 \times 4.6 \mathrm{~mm}$ i.d., $5 \mu \mathrm{m}$ ) (Supelco, Sigma-Aldrich Denmark, Vallensbaek Strand, Denmark). The mobile phase was 75 acetonitrile : 25 water (by volume) at $2 \mathrm{~mL} \mathrm{~min}^{-1}$, the column temperature $35^{\circ} \mathrm{C}$, and the injection volume $50 \mu \mathrm{L}$.

All sensory analyses were carried out on size category 8.75 to $10.2 \mathrm{~mm}$ to eliminate the effect of size on sensory quality. Samples with comparable AIS concentrations within cultivar and year were selected for sensory analyses of nonstressed and stressed peas. By using this methodology we were able to eliminate the effects of maturity on the sensory quality attributes. The impact of maturity on sensory quality was evaluated in 1996 on the size category 8.75 to $10.2 \mathrm{~mm}$. For this test, samples from only two replicates were used.

Sensory analysis was carried out with six trained panelists (Wienberg et al., 2000). A set of 14 descriptive terms was developed, of which six were directly or indirectly related to pea texture (mealiness, skin toughness, seed hardness, crispness, juiciness, and sweetness). Mealiness was defined as the starchlike sensation between the tongue and roof or sides of the mouth. Skin toughness was evaluated as the total amount of work necessary to chew testa to a state ready for swallowing. Seed hardness was defined as the force required to bite completely through peas at first bite when placed between the molars. Crispness was evaluated as the level of higher pitched noise at first bite. Juiciness was evaluated as the amount of juice released on chewing. Evaluations were made on a continuous nonstructured scale with anchor points corresponding to low (0) and high (15) intensity. The peas were evaluated at $18{ }^{\circ} \mathrm{C}$ in accordance with procedures described by Wienberg et al. (2000).

STATISTICAL ANALYSIS. Analysis of variance was performed on each variable using the SAS statistical program version 6 (SAS Institute, 1989). The main effects and interactions were tested using the General Linear Models procedure. The sensory variables were analysed using a mixed model ANOVA, taking the combined residual structure into account (Wienberg et al., 2000).

\section{Results and Discussion}

YIELD AND SIZE DiSTRIBUTION. The yield of nonstressed plants increased as the peas matured (Table 2). The proportion of small seeds decreased while that of large seeds increased. The observed

Fig. 1. Relationship between tenderometer value and concentration of alcoholinsoluble solids (AIS) in ungraded and graded peas as affected by drought stress during pod filling ( $\square$ ) and in nonstressed (O) peas of 'Avola' (solid lines) and 'Novella' (broken lines) in 1996. Standard errors are based on a sample size of three. Regression equations (bold lines) and coefficients of determination $\left(r^{2}\right)$ are based on average of treatments.
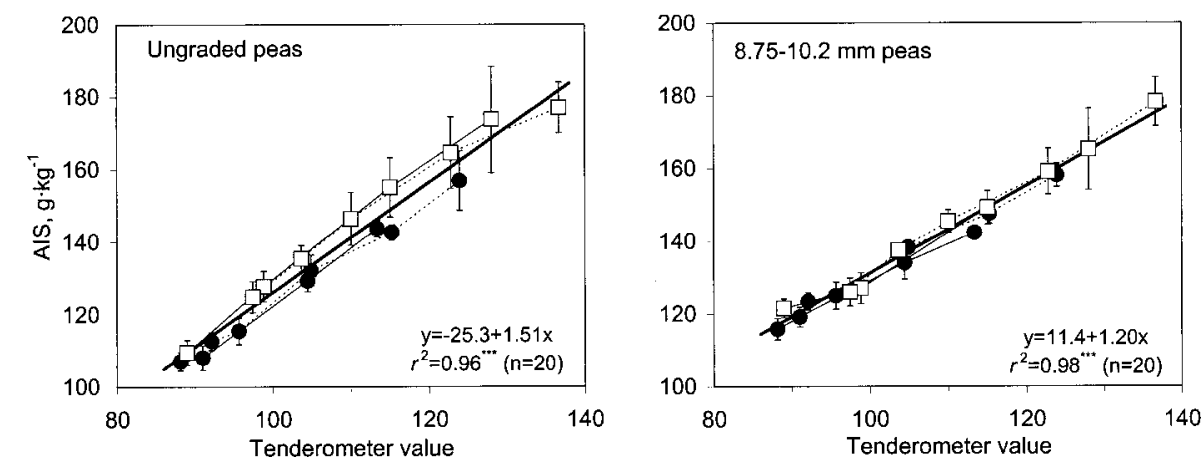
Table 3. Results of linear regression analyses conducted to test the correlation between measured properties of green peas as influenced by cultivars (C) and drought treatments (D).

\begin{tabular}{|c|c|c|c|c|c|c|}
\hline \multirow[b]{2}{*}{ Dependent vs. independent measure } & \multicolumn{3}{|c|}{1995} & \multicolumn{3}{|c|}{1996} \\
\hline & $\mathrm{C}$ & $\mathrm{D}$ & $\mathrm{C} \times \mathrm{D}$ & $\mathrm{C}$ & $\mathrm{D}$ & $\mathrm{C} \times \mathrm{D}$ \\
\hline AIS of ungraded peas vs. Tenderometer value & --- & --- & --- & NS & NS & NS \\
\hline AIS of $8.75-10.2 \mathrm{~mm}$ peas vs. Tenderometer value & --- & --- & --- & NS & NS & NS \\
\hline Pea yield vs. AIS of ungraded peas & NS & * & $* *$ & NS & $* * *$ & NS \\
\hline Proportion of pea size $8.75-10.2 \mathrm{~mm}$ vs. AIS of ungraded peas & NS & NS & $* *$ & NS & $* *$ & $* *$ \\
\hline Mean pea weight vs. AIS of $8.75-10.2 \mathrm{~mm}$ peas & NS & NS & $*$ & NS & NS & * \\
\hline Testa weight vs. AIS of $8.75-10.2 \mathrm{~mm}$ peas & NS & NS & NS & $* *$ & NS & $* *$ \\
\hline Dry matter concentration vs. AIS of $8.75-10.2 \mathrm{~mm}$ peas & NS & NS & NS & NS & NS & NS \\
\hline Starch concentration vs. AIS of $8.75-10.2 \mathrm{~mm}$ peas & NS & NS & NS & NS & NS & $*$ \\
\hline Sucrose concentration vs. AIS of $8.75-10.2 \mathrm{~mm}$ peas & NS & NS & NS & $*$ & $* *$ & $*$ \\
\hline
\end{tabular}

$\overline{\mathrm{Ns}, * * *, * * * *}$ Nonsignificant or significant at $P<0.05,0.01$, or 0.001 , respectively for test of identical slope parameter.

yield increase in nonstressed plants was mainly due to an increase in seed size, which is in agreement with Ottosson (1958).

The concentration of AIS was closely correlated to the TV in ungraded and graded peas and this relation was the same for the two cultivars (Fig. 1). A previous experiment on 11 pea cultivars, however, showed AIS values ranging from 120 to $150 \mathrm{~g} \cdot \mathrm{kg}^{-1}$ at a TV of 110 (Grevsen and Kidmose, 1992). In the present experiment the AIS concentration increased at increased TV in ungraded and graded peas. The AIS concentration of ungraded peas from drought-stressed plants was slightly higher than that from nonstressed plants at the same TV (Fig. 1 and Table 3 ). Although not significant, this tendency is in agreement with Ottosson (1958) who studied the relationship between the TV of ungraded peas and the AIS concentration during four growing seasons and observed that the AIS concentration was lower at the same TV in a rainy season than in a normal season.

We have previously shown that the AIS concentration increased with increased pea size (Hansen et al., 1999). In size category 8.75 to $10.2 \mathrm{~mm}$, drought stress did not significantly increase the AIS concentration at comparable TV (Fig. 1 and Table 3). The nonsignificant increase in AIS of ungraded peas grown under drought stress could be due to an increase in the proportion of large peas. In fact, the proportion of peas in size categories 8.75 to $10.2 \mathrm{~mm}$ (Fig. 2) and $>10.2 \mathrm{~mm}$ increased when drought stress was imposed during the pod-filling stage in 1996. However, this was not the case in 'Avola' grown in 1996. Therefore, the relationship between AIS and TV of peas from drought-stressed plants could not be explained as a result of altered size distribution alone. This conclusion is supported by Salter (1963), who showed that drought stress during the flowering stage reduced the proportion of medium-sized peas and increased that of large-sized peas, whereas drought stress during later growth stages had the opposite effect. In the present experiment, drought stress applied during the flowering stage increased the proportion of size category 8.75 to $10.2 \mathrm{~mm}$ in 'Avola', but reduced that of 'Novella' (Fig. 2 and Table 3). This inconsistency could be due to differences in growth habit of the two cultivars. 'Novella' is a semi-fasciated type, whereas

'Avola' is a normal-indeterminate type, but the physiological mechanism for this reaction is still unclear.

The pea yield increased or was unaffected as maturity increased, i.e. the AIS concentration increased (Fig. 2). The yield of 'Avola' was lower than that of 'Novella'. When drought stress was imposed during the pod-filling stage, the yield of both cultivars was reduced as compared to that of nonstressed plants at a comparable AIS concentration (Table 3). At an AIS concentration of $140 \mathrm{~g} \cdot \mathrm{kg}^{-1}$, the pea yield was reduced by $40 \%$ to $50 \%$ (Fig. 2). The effect of drought stress on yield was more severe during flowering than during the pod filling in 'Avola', but not in 'Novella'. Yield response to shortage of water during different growth stages of peas has been studied by numerous researchers. Maurer et al. (1968), Salter (1963), and Stoker(1973) showed that

Fig. 2. Influence of drought stress during flowering $(\Delta)$ or pod filling $(\square)$ and in non-stressed (-) plants of 'Avola' (solid lines) and 'Novella' (broken lines) on the relationship between alcohol-insoluble solids (AIS) in ungraded peas and the yield of green peas and the proportion of size category 8.75 to $10.2 \mathrm{~mm}$, respectively, in 2 years. Standard errors are based on a sample size of three.

1995
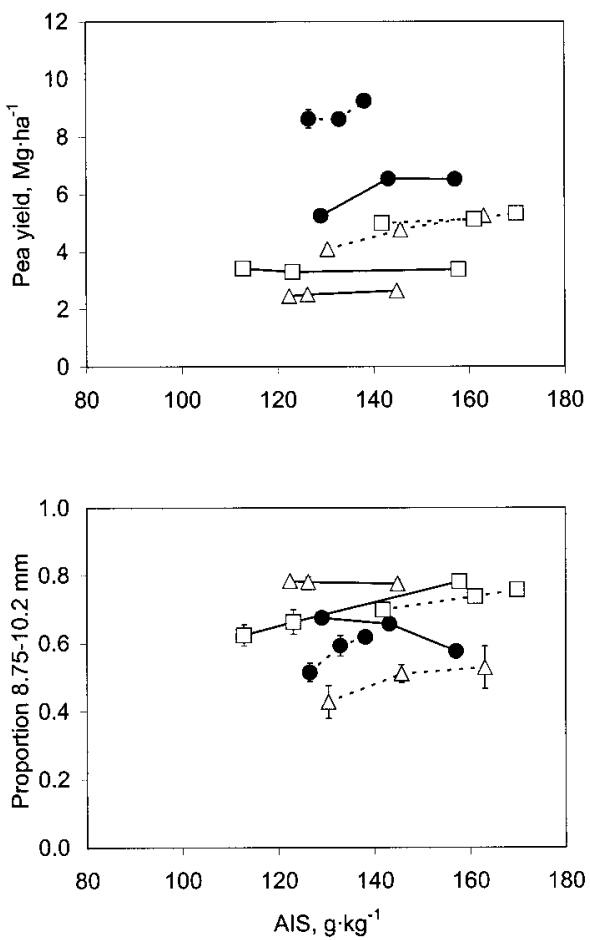

1996
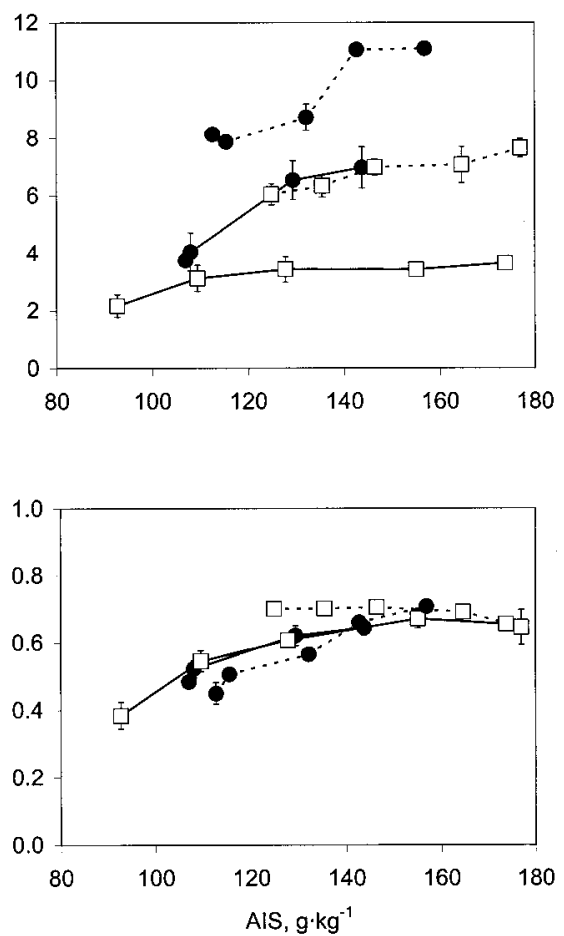
Table 4. Physical properties and chemical composition, on fresh weight basis, of nonstressed peas of varying size categories. Average of three harvest times in 1995. Standard errors are based on a sample size of three.

\begin{tabular}{|c|c|c|c|c|c|}
\hline $\begin{array}{l}\text { Pea size } \\
\text { category } \\
(\mathrm{mm})\end{array}$ & $\begin{array}{c}\text { Mean } \\
\text { pea wt } \\
(\mathrm{mg})\end{array}$ & $\begin{array}{l}\text { Testa wt } \\
\text { fraction } \\
\left(\mathrm{g} \cdot \mathrm{kg}^{-1}\right)\end{array}$ & $\begin{array}{c}\text { AIS } \\
\left(\mathrm{g} \cdot \mathrm{kg}^{-1}\right)\end{array}$ & $\begin{array}{c}\text { Dry } \\
\text { matter } \\
\left(\mathrm{g} \cdot \mathrm{kg}^{-1}\right)\end{array}$ & $\begin{array}{l}\text { Sucrose } \\
\left(\mathrm{g} \cdot \mathrm{kg}^{-1}\right)\end{array}$ \\
\hline & \multicolumn{5}{|c|}{ Avola } \\
\hline$<8.2$ & $204 \pm 2.6$ & $537 \pm 9.1$ & $98 \pm 3.1$ & $192 \pm 2.5$ & $49 \pm 2.1$ \\
\hline $8.2-8.74$ & $276 \pm 1.9$ & $427 \pm 8.1$ & $112 \pm 2.7$ & $210 \pm 2.4$ & $55 \pm 1.9$ \\
\hline $8.75-10.2$ & $364 \pm 4.0$ & $298 \pm 8.8$ & $145 \pm 4.1$ & $250 \pm 3.3$ & $55 \pm 2.4$ \\
\hline$>10.2$ & \multicolumn{5}{|c|}{ Novella } \\
\hline$<8.2$ & $211 \pm 1.8$ & $402 \pm 5.7$ & $102 \pm 2.2$ & $202 \pm 2.6$ & $57 \pm 1.1$ \\
\hline $8.2-8.74$ & $281 \pm 1.7$ & $320 \pm 6.1$ & $119 \pm 1.5$ & $219 \pm 2.8$ & $58 \pm 0.9$ \\
\hline $8.75-10.2$ & $357 \pm 5.3$ & $250 \pm 7.2$ & $145 \pm 1.9$ & $252 \pm 3.9$ & $57 \pm 0.9$ \\
\hline$>10.2$ & $455 \pm 5.8$ & $193 \pm 3.8$ & $174 \pm 4.2$ & $287 \pm 7.6$ & $53 \pm 1.8$ \\
\hline
\end{tabular}

drought stress during flowering or pod filling reduced the yield of green peas. In peas grown for dry seed production, drought stress was more severe during flowering than the pod-filling stage (Jensen, 1987; Jørgensen, 1991; Riley, 1986). However, Miller et al. (1977) found the opposite result and Martin and Jamieson (1996) concluded that the time of drought stress has no effect on pea yield. This inconsistency in the results could be due to cultivar differences (Martin and Tabley, 1981) and the severity of the drought stress imposed. Silim et al. (1992) found that severe drought stress (-1.2 $\mathrm{MPa}$ in soil water potential) imposed during flowering reduced the yield more than an equal stress imposed during pod fill. A less severe drought stress $(-0.4 \mathrm{MPa})$, however, gave the opposite result. Soil water potential gradually decreases during drought stress. Therefore, it takes a longer time to obtain severe than less severe drought stress at an equal water-uptake rate. At severe drought, water must be withheld at an earlier growth stage, which could then influence growth and yield. The severity of drought stress might be better expressed by leaf water potential than by soil water potential.

Physical Characteristics. Size grading is used in the pea processing industry to minimize the variation in pea quality in a batch. In general, mean pea weight increased and testa weight as a fraction of the total weight decreased with increasing pea size (Table 4). These results are in agreement with those of Ros and Rincón (1991). Analogous to pea size, mean pea weight increased with increasing maturity. The mean pea weight of size category 8.75 to $10.2 \mathrm{~mm}$ also increased when drought stress was imposed during the pod-filling stage in 1996, taking the AIS concentration as a criterion of maturity (Fig. 3 and Table 3). However, the mean pea weight was not influenced by drought stress during the pod-filling stage in 1995. Drought stress imposed during the flowering stage increased the mean pea weight in 'Avola', but reduced it in 'Novella' (Fig. 3 and Table 3). In the literature, mean pea weight has been reported to increase, decrease, or be unaffected by drought stress. A reduced number of pod-bearing nodes and a reduced number of peas per pod following drought stress during the flowering and podfilling stages has been reported by Martin and

Jamieson (1996), Maurer et al. (1968), Ney et al. (1994), Pumphrey and Schwanke (1974), and Silim et al. (1992). Furthermore, Silim et al. (1992) and Wilson et al. (1981) observed a reduced leaf area in drought-stressed plants. The increased mean pea weight observed in drought stress treatments in the present experiment may be a result of increased growth of the peas in the remaining pods and of the remaining peas in these pods. This will occur if drought stress has a stronger effect on reducing the number of pods than on photosynthesis and leaf area development. The competition for assimilate between these sinks probably varies according to the growth habit of the cultivar and the stage of development at which drought stress is imposed.

The testa weight decreased with increased AIS concentration

Fig. 3. Relationship between alcohol-insoluble solids (AIS) and mean pea weight and testa weight, respectively, of green peas size category 8.75 to $10.2 \mathrm{~mm}$ from nonstressed plants $(\bullet)$ or drought stressed plants during flowering $(\Delta)$ and podfilling stage ( $\square$ ) of 'Avola' (solid lines) and 'Novella' (broken lines) in 2 years. Standard errors are based on a sample size of three.

1995
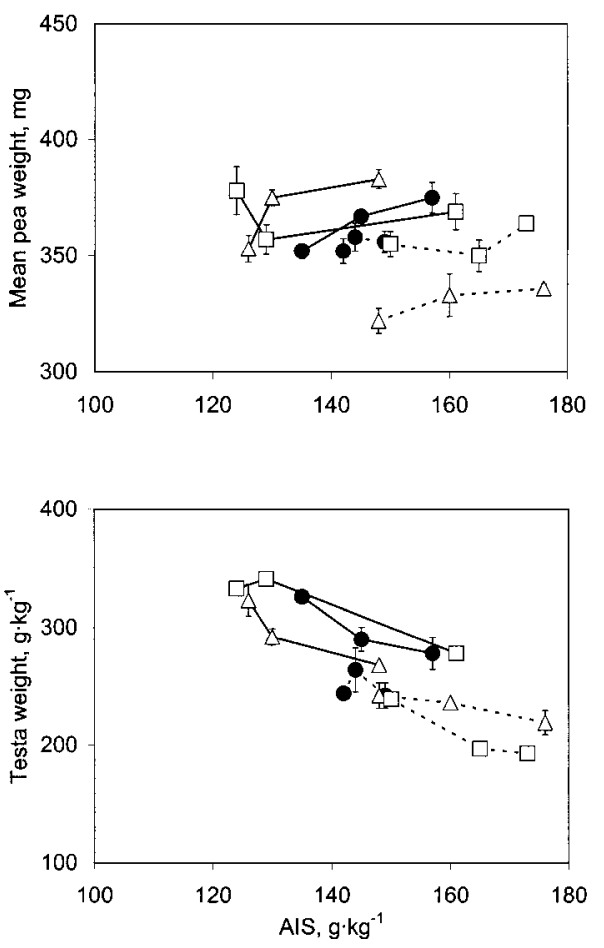

1996
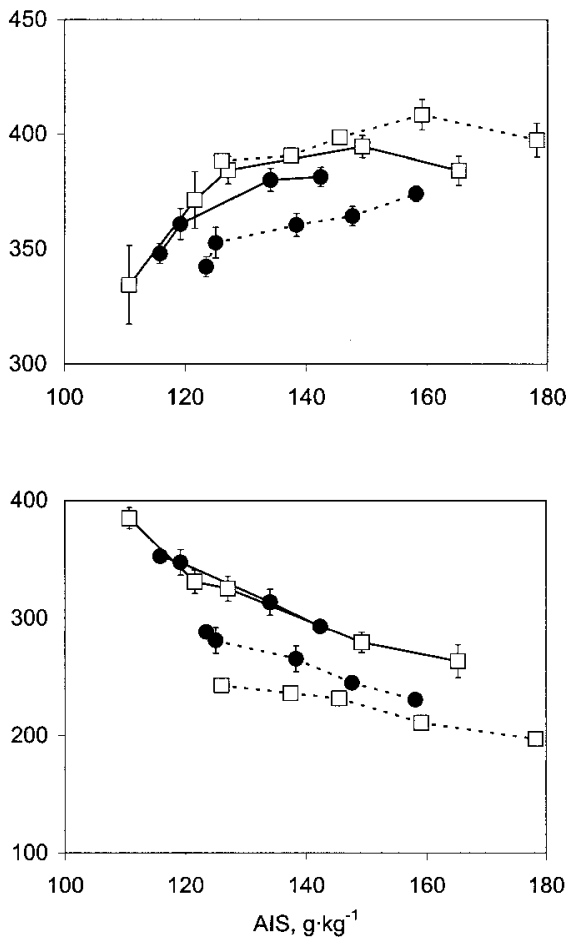

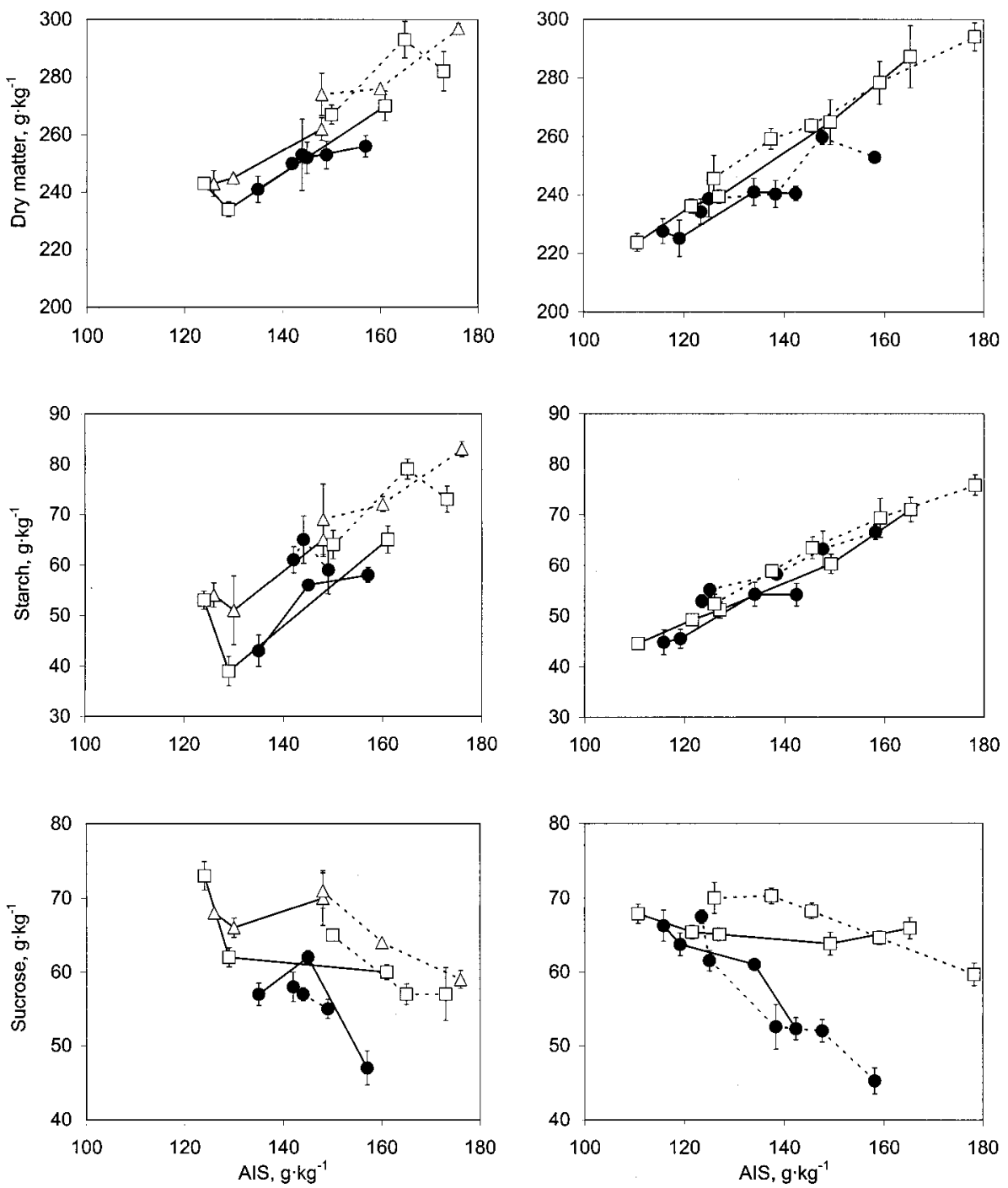

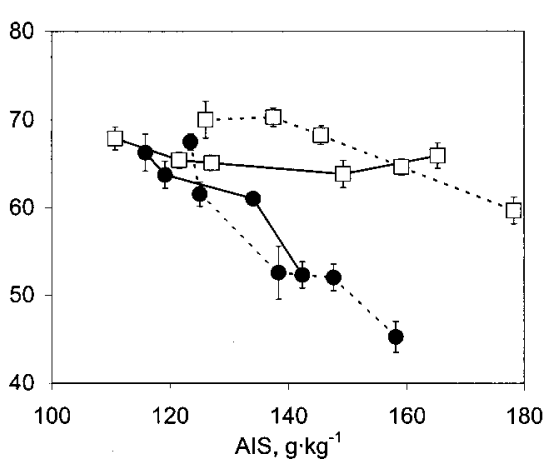

Ottosson (1958) also observed these relationships during the 1950s. The relationship between AIS and the dry matter concentration is unaffected by cultivar (Kidmose and Grevsen, 1992). Wager and Porter (1973) reported that the concentration of sucrose was maximized at an AIS concentration of 110 to $120 \mathrm{~g} \cdot \mathrm{kg}^{-1}$.

Drought stress during flowering or pod filling did not significantly increase the dry matter concentration (Table 3). In general, the effect of drought stress on the chemical composition of green peas is rarely investigated. In a rainy season, Ottosson (1958) observed that the dry matter concentration was lower at the same maturity (TV) as in a normal season. Salter (1963) showed that irrigation given at the pod-filling stage reduced the dry matter concentration of peas. In dry peas the dry matter concentration was increased when drought stress was subjected during the flowering or pod-filling stages (Riley, 1986). About half of the dry matter in peas consisted of starch and sucrose (Fig. 4). In the present experiment, drought stress imposed during the pod-filling stage did not influence the starch concentration in either cultivar (Table 3).

Sucrose was the most important soluble sugar in green peas, accounting for $>95 \%$ of the total soluble sugars. Drought stress imposed during the flowering and pod-filling stages significantly increased the sucrose concentration only in 1996 (Fig. 4 and Table 3). The sucrose concentration decreased at increasing maturity in 1996. However, the concentration declined at a lower rate in peas grown under drought stress than under nonstress conditions. Based on dry matter, the concentration of sucrose was still higher in

Fig. 4. Relationship between alcohol-insoluble solids (AIS) and dry matter, starch, and sucrose, respectively, in fresh weight of peas size category 8.75 to $10.2 \mathrm{~mm}$ from nonstressed plants $(-)$ or drought stressed plants during flowering $(\Delta)$ and pod-filling stage $(\square)$ of 'Avola' (solid lines) and 'Novella' (broken lines) in 2 years. Standard errors are based on a sample size of three.

and increased mean pea weight (Fig. 3), i.e., in younger seeds the testa accounted for a higher proportion of total seed weight than in older and more mature seeds with starch-filled cotyledons. However, significant results were only obtained in 1996 (Table 3).

Chemical Composition. The concentration of AIS and dry matter increased with increased pea size, while that of sucrose was not significantly influenced (Table 4). This agrees with Periago et al. (1996). Dry matter and starch concentration increased with AIS concentration while sucrose concentration decreased for peas in the 8.75 to $10.2 \mathrm{~mm}$ size category (Fig. 4).

Fig. 5. Relationship between scores for sensory evaluation and the concentration of alcohol-insoluble solids (AIS) in fresh matter of peas size category 8.75 to $10.2 \mathrm{~mm}$ from nonstressed 'Novella' plants in 1996. Standard errors are based on a sample size of two.

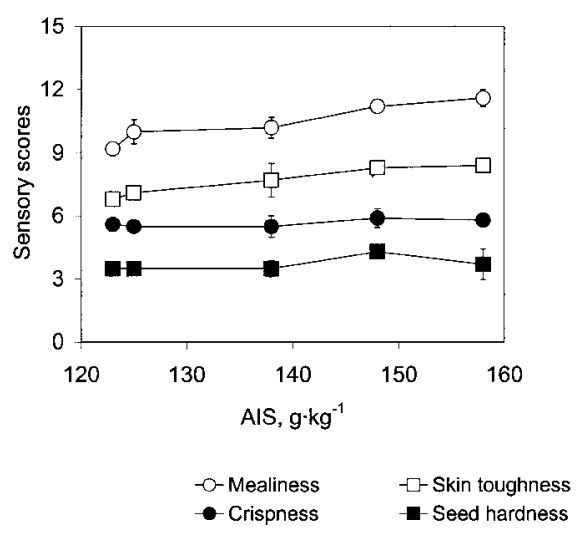

drought-stressed than in nonstressed peas. The influence of drought stress on sucrose accumulation in green peas has not been investigated previously. The concentration of sucrose and other sugars have been reported to increase in leaves of many plant species exposed to drought stress (Nandwal et al., 1993; Sánchez et al., 1998). This is probably caused by osmotic adjustment, which is the active accumulation of solutes within the plant tissue in response to a lowering of soil water potential (Morgan, 1984). Osmotic adjust- 
Table 5. Sensory evaluation of nonstressed and stressed pea samples of size category 8.75 to $10.2 \mathrm{~mm}$. Scores scaled from low (0) to high (15).

\begin{tabular}{|c|c|c|c|c|c|c|c|c|c|}
\hline \multirow[b]{2}{*}{ Year } & \multirow[b]{2}{*}{ Drought period } & \multirow{2}{*}{$\begin{array}{c}\text { AIS } \\
\text { (range) }\end{array}$} & \multirow{2}{*}{$\begin{array}{c}\text { AIS } \\
\text { (mean) }\end{array}$} & \multicolumn{3}{|c|}{ Skin } & \multicolumn{3}{|c|}{ Seed } \\
\hline & & & & Mealiness & Toughness & Hardness & Crispness & Juiciness & Sweetness \\
\hline & & & & & & $\mathrm{g} \cdot \mathrm{k}$ & $\mathrm{g}^{-1}$ & & \\
\hline \multicolumn{10}{|l|}{ Avola } \\
\hline \multirow[t]{3}{*}{1995} & Nonstressed & $131-137$ & $135 \mathrm{a}^{\mathrm{z}}$ & $9.2 \mathrm{a}$ & $7.1 \mathrm{a}$ & $5.2 \mathrm{a}$ & $7.6 \mathrm{a}$ & $5.8 \mathrm{a}$ & $8.1 \mathrm{a}$ \\
\hline & Flowering & $128-133$ & $130 \mathrm{a}$ & $9.5 \mathrm{a}$ & $7.6 \mathrm{a}$ & $4.4 \mathrm{a}$ & $7.6 \mathrm{a}$ & $5.8 \mathrm{a}$ & $7.9 \mathrm{a}$ \\
\hline & Pod fill & $128-131$ & $129 \mathrm{a}$ & $9.6 \mathrm{a}$ & $7.5 \mathrm{a}$ & $5.2 \mathrm{a}$ & $7.9 \mathrm{a}$ & $6.5 \mathrm{a}$ & $8.5 \mathrm{a}$ \\
\hline \multirow[t]{2}{*}{1996} & Nonstressed & $114-124$ & $119 \mathrm{a}$ & $6.5 \mathrm{a}$ & $6.7 \mathrm{a}$ & $4.7 \mathrm{a}$ & $7.0 \mathrm{a}$ & $6.5 \mathrm{a}$ & $8.5 \mathrm{a}$ \\
\hline & Pod fill & $119-127$ & $122 \mathrm{a}$ & $7.3 \mathrm{a}$ & $6.6 \mathrm{a}$ & $4.0 \mathrm{a}$ & $6.8 \mathrm{a}$ & $6.1 \mathrm{a}$ & $8.9 \mathrm{a}$ \\
\hline \multicolumn{10}{|l|}{ Novella } \\
\hline \multirow[t]{3}{*}{1995} & Nonstressed & $145-156$ & $149 \mathrm{a}$ & $10.0 \mathrm{c}$ & $7.7 \mathrm{a}$ & $4.7 \mathrm{a}$ & $7.0 \mathrm{ab}$ & $5.0 \mathrm{a}$ & $7.3 \mathrm{a}$ \\
\hline & Flowering & $140-155$ & $148 \mathrm{a}$ & $10.6 \mathrm{~b}$ & $7.4 \mathrm{a}$ & $4.8 \mathrm{a}$ & $7.4 \mathrm{a}$ & $4.9 \mathrm{a}$ & $7.3 \mathrm{a}$ \\
\hline & Pod fill & $145-155$ & $150 \mathrm{a}$ & $11.6 \mathrm{a}$ & $8.3 \mathrm{a}$ & $4.4 \mathrm{a}$ & $6.5 \mathrm{~b}$ & $4.3 \mathrm{a}$ & $7.7 \mathrm{a}$ \\
\hline \multirow[t]{2}{*}{1996} & Nonstressed & $134-140$ & $138 \mathrm{a}$ & $10.1 \mathrm{a}$ & $7.6 \mathrm{a}$ & $3.5 \mathrm{a}$ & $5.5 \mathrm{a}$ & $4.4 \mathrm{a}$ & $7.5 \mathrm{a}$ \\
\hline & Pod fill & $135-141$ & $137 \mathrm{a}$ & $10.9 \mathrm{a}$ & $7.4 \mathrm{a}$ & $2.8 \mathrm{a}$ & $5.5 \mathrm{a}$ & $3.8 \mathrm{a}$ & $8.7 \mathrm{a}$ \\
\hline
\end{tabular}

${ }^{\mathrm{z}}$ Means followed by the same letter within columns each cultivar and each year are not significantly different $(P<0.05)$.

ment is important in maintaining cell turgor, growth, and photosynthesis.

SEnsory Quality. Previous experiments have shown that the sensory quality of green peas is strongly correlated to pea maturity (Kidmose and Grevsen, 1992). This is partly due to pea size, which greatly influences the concentration of AIS (see Table 4). To eliminate the effects of pea size all sensory analyses were carried out on size category 8.75 to $10.2 \mathrm{~mm}$. At increasing maturity (increased AIS concentration), peas became more mealy and tough with less juice and sweetness (Fig. 5). Therefore, to eliminate the effects of maturity on sensory quality we selected samples with comparable AIS concentration within each cultivar and year for the studies on drought effects (Table 5). Although the AIS concentration varied, the mean was not significantly influenced by the different treatments.

Drought stress imposed during flowering or pod filling did not significantly increase the scores for mealiness except in 'Novella' in 1995 (Table 5). The scores for skin toughness and seed hardness were not significantly influenced by drought stress; nor were the scores for crispness, juiciness, and sweetness (Table 5). Although not significant, the scores for mealiness and sweetness tended to increase in peas subjected to drought stress as compared to nonstressed peas.

\section{Conclusion}

Although the yield of green peas was reduced dramatically by drought stress during flowering and pod filling, its influence on physical, chemical, and sensory texture quality was minimal and often varying when the effect of maturity on texture quality was eliminated. Neither the mean pea weight nor the testa weight were clearly influenced by drought stress.

At increased maturity the sucrose concentration decreased in peas of size category 8.75 to $10.2 \mathrm{~mm}$. This decrease was greater in nonstressed than drought-stressed peas. The concentration of dry matter and starch were unaffected by drought stress. Mealiness and other texture attributes were unaffected by drought stress at comparable maturity except in one of four occasions. Texture quality was not influenced by the timing of drought stress.

When green peas are harvested at optimum maturity, their texture quality is only slightly influenced by drought stress. As texture quality is highly correlated to stage of maturity, the TV and AIS concentration are reliable measurements of maturity in the production of high quality peas irrespective of drought-stress conditions during maturation.

\section{Literature Cited}

AOAC. 1990. Official methods of analysis. 15th ed., AOAC, Arlington, Va.

Best, E.K. 1976. An automated method for determining nitrate-nitrogen in soil extracts. Queensland J. Agr. Animal Sci. 33:161-166.

Crooke, W.M. and W.E. Simpson. 1971. Determination of ammonium in kjeldahl digest of crops by an automated procedure. J. Sci. Food Agr. 22:9-10.

Edelenbos, M., A. Thybo, L. Erichsen, L. Wienberg, and L. Andersen. 2001. Relevant measurements of green pea texture. J. Food Qual. 24:91-110.

Forskningsforeningen. 1999. Den strategiske ært. Forskningsforeningen for Forarbejdet Frugt og Grønt, Copenhagen.

Grevsen, K. and U. Kidmose. 1992. Yield, plant growth and quality of vining pea varieties at early and late sowing dates. Tidsskr. Planteavl 96:279-292.

Hansen, M., J.N. Sørensen, and L. Wienberg. 1999. Changes in the chemical and sensory quality of green peas during development, $\mathrm{p}$. 134-137. In: M. Hägg, R. Ahvenainen, A.M. Evers, and K. Tiilikkala (eds.). Agri-Food II: Quality management of fruits and vegetables. Royal Soc. Chem., Cambridge.

Jensen, F. 1987. Irrigation requirement in various growing phases of peas (in Danish). Tidsskr. Planteavl 91:113-119.

Jørgensen, U. 1991. Drought in different growth phases in peas. Growth, nutrient uptake and yield (in Danish). Tidsskr. Planteavl 95:171-179.

Kidmose, U. and K. Grevsen. 1992. Quality of vining pea varieties for deep freezing. Tidsskr. Planteavl 96:353-360.

Kjølstad, L., T. Isaksson, and H.J. Rosenfeld. 1990. Prediction of sensory quality by near infrared reflectance analysis of frozen and freeze dried green peas (Pisum sativum). J. Sci. Food Agr. 51:247-260.

Martin, R.J. and P.D. Jamieson. 1996. Effect of timing and intensity of drought on the growth and yield of field peas (Pisum sativum L.). N.Z. J. Crop Hort. Sci. 24:167-174.

Martin, R.J. and F.J. Tabley. 1981. Effects of irrigation, time of sowing and cultivar on yield of vining peas. N.Z. J. Expt. Agr. 9:291-297.

Martin, W.M. 1937. The tenderometer. An apparatus for evaluating the tenderness in peas. Canning Trade 59:7-14.

Maurer, A.R., D.P. Ormrod, and H.F. Fletcher. 1968. Response of peas to environment. IV. Effect of five soil water regimes on growth and development of peas. Can. J. Plant Sci. 48:129-137.

Miller, D.G., C.E. Manning, and I.D. Teare. 1977. Effects of soil water levels on components of growth and yield in peas. J. Amer. Soc. Hort. Sci. 102:349-351. 
Morgan, J.M. 1984. Osmoregulation and water stress in higher plants. Annu. Rev. Plant. Physiol. 35:299-319.

Nandwal, A.S., S. Bharti, M.S. Kuhad, and J. Singh. 1993. Response of pigeon pea cultivars to water stress. Biol. Plant. 35:641-644.

Ney, B., C. Duthion, and O. Turc. 1994. Phenological response of pea to water stress during reproductive development. Crop Sci. 34:141-146.

Ottosson, L. 1958. Growth and maturity of peas for canning and freezing. Almqvist \& Wiksell, Uppsala.

Periago, M.J., G. Ros, C. Martínez, F. Rincón, G. Lopez, J. Ortuño, and J. Rodrigo. 1996. Relationships between physical-chemical composition of raw peas and sensory attributes of canned peas. J. Food Qual. 19:91-106.

Pumphrey, F.V. and R.K. Schwanke. 1974. Effects of irrigation on growth, yield, and quality of peas for processing. J. Amer. Soc. Hort. Sci. 99:104-106.

Riley, H. 1986. Drought periods at different growth stages of peas (in Norwegian). Forsk. Fors. Landbr. 37:105-113.

Ros, G. and F. Rincón. 1991. Size dependence of color, texture and nutritional qualities of canned pea (Pisum sativum). Food Sci. Technol. 24:549-552.

Salter, P.J. 1963. The effect of wet and dry soil conditions at different growth stages on the components of yield of a pea crop. J. Hort. Sci. 38:321-334.
Sánchez, F.J., M. Manzanares, E.F. de Andres, J.L. Tenorio, and L. Ayerbe. 1998. Turgor maintenance, osmotic adjustment and soluble sugar and proline accumulation in 49 pea cultivars in response to water stress. Field Crops Res. 59:225-235.

SAS Institute Inc. 1989. SAS/STAT user's guide. version 6. 4th ed. vol 2. SAS Institute Inc, Cary, N.C.

Silim, S.N., P.D. Hebblethwaite, and C. Jones. 1992. Irrigation and water use in leafless peas (Pisum sativum). J. Agr. Sci. Camb. 119:211-222.

Sørensen, N.K. and A. Bülow-Olsen. 1994. Fælles arbejdsmetoder for jordbundsanalyser. Plantedirektoratet, Lyngby.

Stoker, R. 1973. Response of viner peas to water during different phases of growth. N.Z. J. Expt. Agr. 1:73-76.

Voisey, P.W. and I.L. Nonnecke. 1973. Measurement of pea tenderness. II. A review of methods. J. Texture Stud. 4:171-195.

Wager, H.G. and F.A.E. Porter. 1973. The effect of maturity on the texture of the testa and cotyledon of peas (Pisum sativum). J. Food Technol. 8:121-131.

Wienberg, L., M. Martens, and P.B. Brockhoff. 2000. Sensory quality criteria for cold versus warm green peas studied by multivariate data analysis. J. Food Qual. 23:565-581.

Wilson, D.R., R. Hanson, and W.A. Jermyn. 1981. Growth and water use of conventional and semi-leafless peas. Proc. Agron. Soc. N.Z. 11:3539. 